University of Nebraska - Lincoln

DigitalCommons@University of Nebraska - Lincoln

USDA National Wildlife Research Center - Staff Publications
U.S. Department of Agriculture: Animal and Plant Health Inspection Service

2018

\title{
The effect of wildfire on population dynamics for two native small mammal species in a coastal heathland in Queensland, Australia
}

Adam C. Liedloff

CSIRO, Adam.Liedloff@csiro.au

John C. Wilson

Queensland University of Technology

Richard M. Engeman

USDA National Wildlife Research Center, s_r100@yahoo.com

Follow this and additional works at: https://digitalcommons.unl.edu/icwdm_usdanwrc

Part of the Life Sciences Commons

Liedloff, Adam C.; Wilson, John C.; and Engeman, Richard M., "The effect of wildfire on population dynamics for two native small mammal species in a coastal heathland in Queensland, Australia" (2018). USDA National Wildlife Research Center - Staff Publications. 2109.

https://digitalcommons.unl.edu/icwdm_usdanwrc/2109

This Article is brought to you for free and open access by the U.S. Department of Agriculture: Animal and Plant Health Inspection Service at DigitalCommons@University of Nebraska - Lincoln. It has been accepted for inclusion in USDA National Wildlife Research Center - Staff Publications by an authorized administrator of DigitalCommons@University of Nebraska - Lincoln. 


\title{
The effect of wildfire on population dynamics for two native small mammal species in a coastal heathland in Queensland, Australia
}

\author{
Adam C. Liedloff ${ }^{\mathrm{a}, \mathrm{b}}$, John C. Wilson ${ }^{\mathrm{b}, 1}$, Richard M. Engeman ${ }^{\mathrm{c}, *}$ \\ ${ }^{a}$ CSIRO, PMB 44, Winnellie, Northern Territory, 0822, Australia \\ b School of Natural Resource Sciences, Queensland University of Technology, GPO Box 2434, Brisbane, Queensland, 4001, Australia \\ ${ }^{\mathrm{c}}$ National Wildlife Research Center, 4101 LaPorte Ave, Fort Collins, CO, 80521-2154, USA
}

\section{A R T I C L E I N F O}

\section{Keywords:}

Bribie island

Grassland melomys

Mark-recapture

Melomys burtoni

Rattus lutreolus

Swamp rat

\begin{abstract}
A B S T R A C T
The influences of wildfire through population dynamics and life history for two species of small mammals in a south-east Queensland heathland on Bribie Island are presented. Trapping results provided information on breeding, immigration and movement of Melomys burtoni (Grassland melomys) and Rattus lutreolus (Swamp rat). We first investigated and optimized the design of trapping methodology for producing mark-recapture population estimates to compare two adjacent populations, one of which was subjected to an extensive wildfire during the two year study. We consider how well rodents survive wildfire and whether the immediate impacts of fire or altered habitat have the greatest impact on each species. We found the R. lutreolus population was far more influenced by the fire than the $M$. burtoni population both immediately after the fire and over 18 months of vegetation recovery.
\end{abstract}

\section{Introduction}

Many Australian plant communities, including the coastal heathlands of south eastern Australia, have evolved with fire disturbance. Plant species in fire-adapted communities often have mechanisms to aid survival from fire (e.g., Land for Wildlife Queensland, 2016a; Watson, 2001, 2002), and numerous plant species benefit from fire at some stage of their life cycles, employing species survival strategies such as resprouting from epicormic buds and lignotubers, using nutrient pulses, or having seeds held by the plant until burned or requiring fire to germinate (Gill, 1975; Karolak, 2005; Land for Wildlife Queensland, 2016a; Watson, 2001, 2002). Fauna, on the other hand, must not only cope with immediate mortality through exposure to fire, heat and smoke, but perhaps more importantly, must cope with modified habitat and recolonization (Catling, 1986; South East Queensland Fire and Biodiversity Consortium, 2014; Karolak, 2005; Land for Wildlife Queensland, 2016b; Watson, 2001, 2002). Fire impacts on habitat extend to factors such as quality and distribution of food resources (including insects reliant on removed vegetation), vulnerability to predation, and the abundance and distribution of structure used as shelter (Cowley et al., 1969; Watson, 2001, 2002), possibly making fauna more vulnerable to fire than the flora (Newsome et al., 1975). Various strategies allow animal species to improve their chances for survival; such as moving away from fire or sheltering in refuges, especially underground, while some species may lose individuals and recolonize from populations unaffected by the fire (Karolak, 2005; Land for Wildlife Queensland, 2016b; Watson, 2001, 2002). A variety of factors also affect population recovery after a fire, especially the size and severity of the fire, the amount of unburned or refuge areas from which fauna can recolonize, and the degree to which survivors are faced with diminished resources, competition from other animals, unfamiliar habitat and predation (Karolak, 2005; Lindenmayer et al., 2005; Land for Wildlife Queensland, 2016b; South East Queensland Fire and Biodiversity Consortium, 2006).

We conducted a mark-recapture trapping study in a relatively undisturbed area of coastal heathland on Bribie Island (Queensland, Australia) on the island's two most abundant native rodent species: the grassland melomys (Melomys burtoni) and the eastern swamp rat (Rattus lutreolus lutreolus). Melomys burtoni is a small native rodent found from northern New South Wales northward along the Queensland and Northern Territory coasts and islands. It is often associated with grassland habitats, low lying environments and sugar cane crops (Knox, 1978; Baverstock et al., 1981; Watts and Aslin, 1981; Woinarski et al., 1999). This species of mosaic tailed rat has a longevity that can exceed 2 years (Watts and Kemper, 1989). Relatively little is known about $M$. burtoni reproduction, other than it has a relatively low reproductive

\footnotetext{
* Corresponding author.

E-mail address: richard.m.engeman@aphis.usda.gov (R.M. Engeman).

${ }^{1}$ Deceased.
} 
output, with a typical litter size of 2-3 (Dyer et al., 2011; McDougall, 1946; Watts and Aslin, 1981; Watts and Kemper, 1989). While the gestation period and number of litters per year is unknown for this species, the closely related $M$. cervinipes has a gestation period of 38 days (Geffen et al., 2011). In contrast, Bribie Island and south-east Queensland is in the northern range of our other study species, Rattus lutreolus lutreolus (referred to as $R$. lutreolus from this point onward), which ranges south through southern and eastern Australia primarily inhabiting lowlands near the coast. These rats prefer thick vegetation, especially along watercourses and in swamps (e.g., Fox and Monamy, 2007). As a true rat, this species has a higher reproductive output, as females may have several litters of 3-5 young per year, with a gestation period of 22 days (Geffen et al., 2011; Monamy, 1995; Strahan, 1995). Its longevity usually does not exceed 1 year in the wild (Braithwaite and Lee, 1979; Lunney, 1978), although a 29-month lifespan has been recorded (Watts, 1982).

During the course of our study an intense wildfire swept through much of Bribie Island, including one of our two study sites, thereby producing a treatment versus control opportunity to examine the response of both species' populations to wildfire. Thus, in our study we aimed to: 1) investigate how populations of these two species coped with wildfire's direct impacts as well as the resulting altered habitats, and 2) to also obtain measures of their population dynamics and population sizes from which future monitoring in this region can be based.

\section{Methods}

\subsection{Study sites}

Our study was conducted on Bribie Island $\left(26^{\circ} 59^{\prime} 38^{\prime \prime} \mathrm{S}, 153^{\circ} 9^{\prime} 33^{\prime \prime}\right.$ E), located on the southern coast of Queensland, Australia. Our study area was on the east coast of the island in a relatively undisturbed reserve consisting of coastal heathland, swamp, dunes and two forest types, Melaleuca quinquenervia (paper barked tea tree) open forest and woodland and Melaleuca quinquenervia - Eucalyptus robusta open forest (Elsol and Sattler, 1979). We established two study sites (4.34 and $3.98 \mathrm{ha}$ ), $228 \mathrm{~m}$ apart, and separated by a crude beach access track acting as a fire break.

Wildfire burned a large area of native vegetation and Pinus elliotii (slash pine) plantation on Bribie Island during mid November 1994 (Fig. 1). The fire was intense and removed all understorey vegetation to reveal bare ground. The southern site (Site 1) and an adjacent area to the south were not burned $\left(\sim 1 \mathrm{~km}^{2}\right.$ total unburned area of surrounding $20 \mathrm{~km}^{2}$ ). No other areas (including Site 2 and all dune habitats) within $5 \mathrm{~km}$ of the study area escaped the wildfire. For both study sites, there was a zone of $M$. quinquenervia open forest with a swamp-based understory habitat (13-16\% of site area) behind the beach ridge open scrub, potentially providing animals with a fire refuge in the burned site. While the fire removed all ground litter and vegetation other than mature trees in this habitat, the root material survived in the damp, unburned layer, resulting in rapid regrowth. Two months after the fire the ground layer of the swamp zone had recovered with vegetation cover equal to that before the fire, with shrub species taking longer to recover. In contrast, all vegetation in open heathland habitat was removed to reveal a sandy substrate. Although many plant species reappeared after 3 months, recovery was slower than in the swamp habitat, and was still recovering 21 months after the fire due to the slow growth of the shrub and tree layer species. The Melaleuca quinquenervia - Eucalyptus robusta woodland habitat held a thick matted understorey of grasses and sedges producing complex structure up to $75 \mathrm{~cm}$ in height before the fire. While 7 months after the fire the vegetative cover at about $50 \mathrm{~cm}$ was similar to before the fire, the matted nature of the ground vegetation only began to reappear 18 months after the fire. The beach ridge open scrub habitat was severely damaged by the fire, with virtually all ground and shrub vegetation removed and a large number of mature trees defoliated or completely removed. Most of this habitat

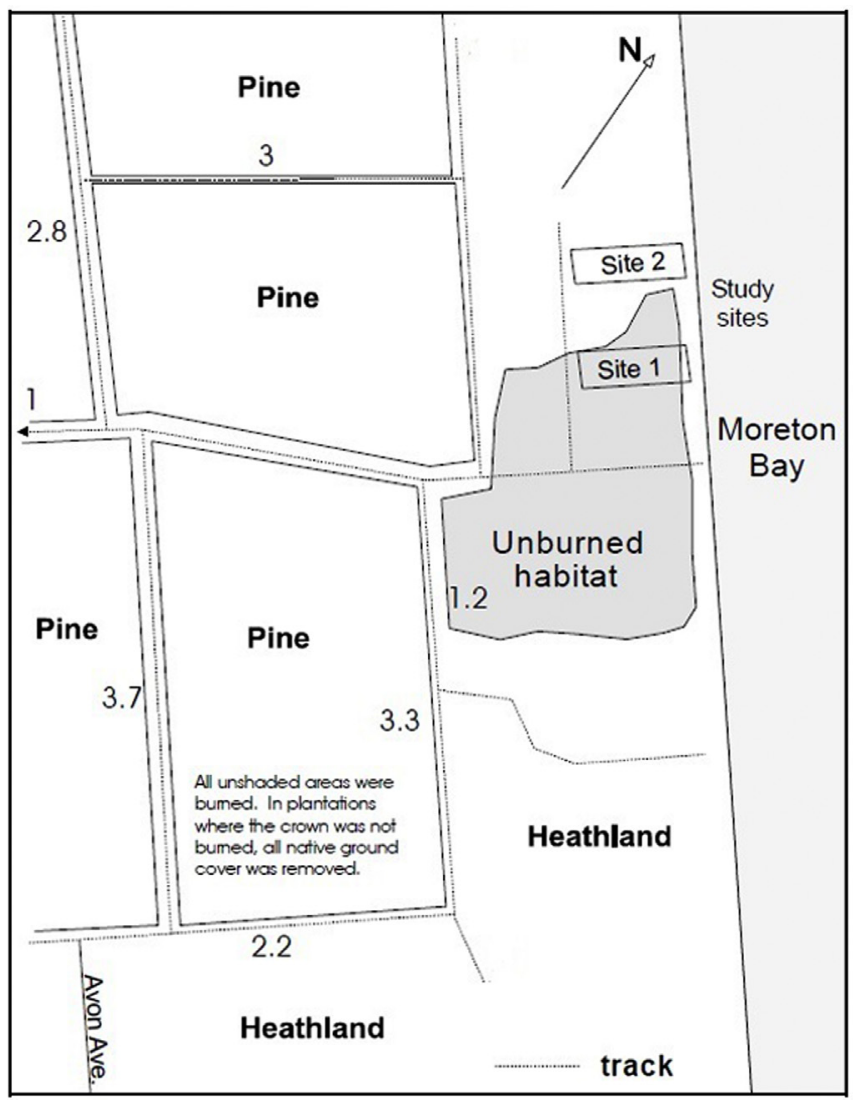

Fig. 1. Map showing the location of the study sites on Bribie Island, Queensland, Australia, and the areas burned by wildfire.

remained bare sand with no canopy after 6 months, with many of the tree and shrub species still recovering after 18 months and some species not observed again after the fire.

\subsection{Trapping design, methodology, and analyses}

We applied mark-recapture field procedures aimed at providing estimates of population size and variance for two species and to compare the two sites. We were in the fortunate position to have access to results from a previous trapping study at Site 1 and we used that information to conduct an additional eleven night pilot study at the same site. Both of these sources of information were used to comprehensively design our study to minimize the potential for violating the underlying assumptions necessary for valid mark-recapture population size estimation, especially satisfying the main assumptions of population closure and equal probability of capture among all individuals on each occasion. Almost every aspect of the trapping regime can affect capture probabilities, including trap placement, the number of nights trapped, and the time of the study. It is critical to consider all these before trapping commences. Apart from ensuring equal capture probabilities, the primary objective of the trapping regime is to ensure that the greatest number of captures possible are obtained, both in terms of the number of individuals caught and the number of recaptures. Access to traps as a result of trap placement can be a cause of capture heterogeneity and so the methodology used must ensure that traps are accessible to the entire population. Temporal variability in the probability of capture is often associated with the number of nights trapped. Using the minimum number of trapping nights required to obtain adequate data without violating the closed population assumption due to breeding and migration will reduce temporal variability.

The detailed preliminary information indicated that our design at each site using 5 parallel traplines, spaced $23 \mathrm{~m}$ apart, with traps 
located every $10 \mathrm{~m}$ along the traplines would be sufficient to: avoid trap saturation, result in about three-quarters of the populations being caught within 5 nights, result in similar numbers of captures each trapnight, and allow individuals to freely move more than the inter-trap distance in the east-west direction (6 traps on average) while not being confined to a single trapline (movements across 2-4 traplines on average).

Trapping was conducted for five nights every month from July 1994 to June 1996 (except for May 1996 when flooding made the study area inaccessible) using a grid of 192 traps (43470 trapping nights), and 176 traps (39560 trapping nights) at Site 1 and Site 2, respectively. At each trap location a single collapsible small mammal trap $(33 \times 10 \times 9 \mathrm{~cm}$, Elliott Scientific, Upwey Victoria) was set, baited with a mixture of peanut butter and rolled oats and checked and cleared each morning after sunrise. Upon first capture each individual was uniquely marked by toe clipping. For all captures, the trap position, species, sex, reproductive condition and head-body length were recorded and the individual was released at the point of capture. Males were considered mature when testes were scrotal while females were classed mature after the vagina became perforate. Females were also classed as pregnant in the late stages of pregnancy by palpation.

Head-body lengths were used as an indication of the age of individuals. Live weight measurements were considered too variable for assessing age, because total body weight for small mammals could be affected by the fullness of the stomach and bladder, the amount of bait consumed and pregnancy in females. The size class delineation between immature and mature M. Burtoni individuals was $110 \mathrm{~mm}$ for each sex, with these individuals approximately ten weeks old (Redhead, 1973), and a head-body length of $80 \mathrm{~mm}$ or less represented recently independent individuals approximately three to four weeks old (Redhead, 1973; Taylor and Horner, 1973). Similar to M. Burtoni, juvenile R. lutreolus with head-body lengths of $110 \mathrm{~mm}$ or less were considered recently independent, and less than 40 days old with individuals $70-80 \mathrm{~mm}$ being $12-20$ days old, while both male and female were found to mature from 140 to $150 \mathrm{~mm}$ in head-body length representing an age between 100 and 130 days old (Fox, 1979; Taylor and Horner, 1973).

\section{Results}

\subsection{General capture results}

Besides $M$. burtoni and $R$. lutreolus, incidental captures of nontarget species included 2 introduced rodent species, house mice (Mus domesticus, 198 individuals captured all months, both sites combined) and black rats ( $R$. rattus, 48 individuals captured all months, both sites combined), as well as 3 other native species: common planigale (Planigale maculata, 4 individuals captured all months, both sites combined), water rat (Hydromys chryogaster, 1 individual captured all months, both sites combined), and brush-tailed phascogale (Phascogale tapoatafa, 1 individual captured all months, both sites combined).

Both $M$. burtoni and $R$. lutreolus were readily caught by live trapping with some individuals caught four or five times each month. The mean number of $M$. burtoni captures per individual per month was 2.62 ( $\mathrm{se}=0.05, \mathrm{n}=791$ ) for males and 2.73 (se $=0.05, \mathrm{n}=612$ ) for females. The average number of $R$. lutreolus captures per individual per month was 2.87 (se $=0.08, \mathrm{n}=366$ ) for males and 3.03 (se $=0.07$, $\mathrm{n}=391$ ) for females. Trap saturation was not an issue, as $90 \%$ of the trappable $M$. burtoni individuals were caught on the first four nights in 18 of the 23 months. Behavioral, temporal and heterogeneity effects on captures were found at both sites between sexes, captures between wet and dry habitat, and between immature and mature strata.

The null model $\left(\mathrm{M}_{0}\right)$ from programs CAPTURE or MARK (White and Burnham, 1999) provided a general indication of the probability of capture for $M$. burtoni and $R$. lutreolus each month at each site. For a particular data set, CAPTURE can be applied to select the most appropriate model, including accommodating sources of capture heterogeneity. The null model is the one usually selected as most appropriate for small data sets even though a different model might better represent the underlying population (e.g., Hammond and Anthony, 2006). In such cases the investigator must be aware of small sample limitations of CAPTURE, and that $\mathrm{M}_{0}$ is unlikely to be the most suitable model (e.g., Hammond and Anthony, 2006). Notwithstanding its functionality, CAPTURE requires large amounts of data for the chisquare goodness-of-fit tests for model selection (e.g., Hammond and Anthony, 2006). In particular, CAPTURE has been found to frequently fail to correctly select the model for simulated data sets having $<50$ individuals, thereby producing biased estimates that result from an inappropriate model (Hammond and Anthony, 2006; Menkens and Anderson, 1988; White et al., 1982). For useful capture-recapture results, Hammond and Anthony (2006) recommended that using $>5$ trapping sessions resulting in $\geq 40$ individuals captured and capture probability $>0.2$ for CAPTURE's model selection criteria to be considered reliable. Additionally, open population models (Jolly, 1965; Seber, 1965) also exist for estimating population size while accommodating deaths, births, or immigration and emigration. Unfortunately, open model estimation requires even larger data sets ( $>100$ captures/ occasion) (Jolly, 1965). As seen below, our capture results necessitated rethinking how to characterize the population sizes each month of the study.

Specifically in our case, and given that a target population greater than 50 individuals is required when capture probabilities are around 0.4 or 0.5 and that 200 individuals are necessary when capture probabilities fall to 0.2 (Otis et al., 1978), the population sizes we witnessed in this study seldom provided enough individuals to accurately estimate the population size. Considering that mean probabilities of capture for M. burtoni were 0.519 (se $=0.018$ ) at Site 1 and $0.543(\mathrm{se}=0.017$ ) at Site 2 , at least 50 individuals would have been required to provide an accurate estimate of population size. Importantly, such required sample sizes were greater than the average population sizes of $28.8(\mathrm{se}=2.91$ ) and 33.0 ( $\mathrm{se}=2.64$ ) individuals caught at Site 1 and 2 respectively. The capture probabilities and number of $M$. burtoni were sufficient to calculate a population estimate in only 3 months at Site 1 and 5 months at Site 2. Similar probabilities of capture for $R$. lutreolus of $0.586(0.016)$ at Site 1 and $0.590(0.026)$ at Site 2 also required populations of around 50 individuals. However, the average populations found for $R$. lutreolus of $23.3(\mathrm{se}=1.20)$ at Site 1 and $9.7(\mathrm{se}=1.67)$ suggest that trapping data estimates for this species also would likely be biased.

The number of individuals added to the capture frequency by the 'Known to Be Alive' (KTBA) calculation (Caughley and Sinclair, 1994; Hopkins and Kennedy, 2005; Madsen and Shine, 1999; McKelvey and Pearson, 2001) was very low for both species. On average less than two individuals were KTBA but not caught during each trapping period. A maximum of four additional individuals were added to $M$. burtoni and $R$. lutreolus capture frequencies in any month. With a high probability of capture for $M$. burtoni and $R$. lutreolus in this study, relatively low movements determined in the preliminary and pilot studies, and a small difference between the capture frequency and KTBA, the KTBA method produced only minimal changes to the capture frequency. The number of individuals caught each month severely limited the use of population estimators while the frequency of capture provided a good index of population size for this study and is used for analytical purposes.

\subsection{General population dynamics}

\subsubsection{Melomys burtoni}

The number of $M$. burtoni caught each month (Fig. 2a) ranged from 12 to 57 individuals at Site 1 (3.0/ha to $14.4 /$ ha) and from 13 to 51 individuals at Site $2(3.9 / \mathrm{ha}$ to $15.2 / \mathrm{ha})$. Ignoring the month immediately after the fire (December 1994), we wanted to evaluate whether the population levels observed at both sites were a product of 
a

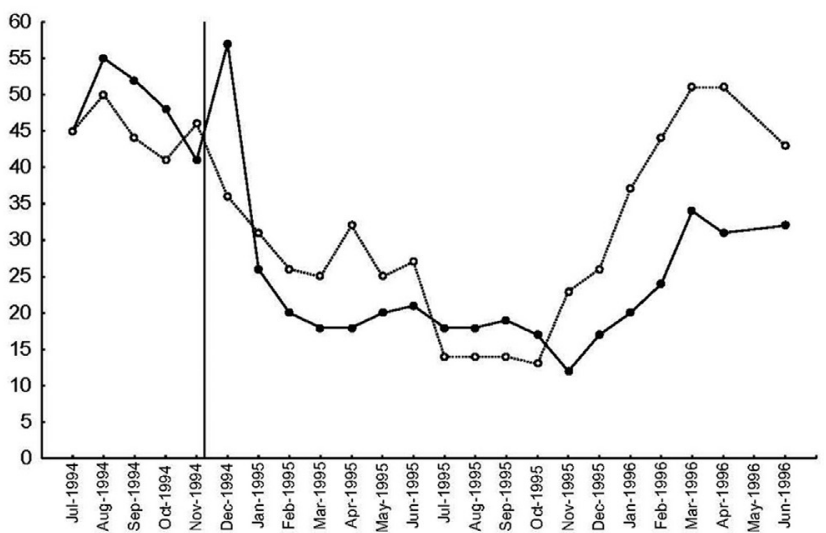

b



Fig. 2. Number of individual (a) Melomys burtoni and (b) Rattus lutreolus caught each month at study Site $1(\bullet)$ and study Site $2(\bigcirc)$ on Bribie Island, Queensland, Australia. The vertical line shows the time at which the wildfire occurred at Site 2 .

sequentially random fluctuations or if a non-random pattern was indicated. Runs tests above and below the median (Sokal and Rohlf, 1995) revealed that the population changes at both sites represented real trends and were not the result of random fluctuations (critical $u_{0.05(1), 10,11} \geq 7$, Site $1, u_{10,11}=3$; site $2, u_{10,11}=3$ ), with both populations displaying similar trends. A comparison of capture frequencies revealed a difference between the two sites (Wilcoxon signed rank test, paired by month. $\left.\mathrm{Z}_{(0.05,22)}=2.54, \mathrm{p}=0.011\right)$ due to the different magnitude of population increases after October 1995 (a year after the fire). No difference in the capture frequencies between the sites was found when the months prior to November 1995 were tested $\left(\mathrm{Z}_{0.05,15}=0.63, \mathrm{p}=0.53\right)$.

The monthly breakdown of the population into sex and reproductive status at each site suggested trickle breeding, with (late stage) pregnant females found in the majority of months. The lowest number of immature individuals was found during October each year with the largest numbers of new individuals entering the populations $(30-50 \%$ new captures) during spring and summer and an average monthly recruitment of $27 \%$ (se $=14$ at Site 1,12 at Site 2). Individuals caught for the first time and classified as a result of breeding $(<80 \mathrm{~mm})$ were found between October and May each year. Between 15 and 20 of these individuals were recorded at each site each year.

Immigration of mature individuals into each study site was low, which was a logical expectation because we observed few individuals moving between the two study sites. By the second month of trapping, the average number of adults found to immigrate into the sites in the remaining months (except December 1994) was 2.14 (se $=0.52$ ) at Site 1 and $2.62(\mathrm{se}=0.38)$ at Site 2 . The remaining recruitment was immature individuals greater than $80 \mathrm{~mm}$ in length. After August 1994 (excluding December 1994) the average number of individuals in this category was $2.86(\mathrm{se}=0.66)$ at Site 1 and $3.19(\mathrm{se}=0.72)$ at Site 2 .

As an indicator of residency time, $61.9 \%$ of $M$. burtoni were caught in at least two months. There was no difference in mean residency time between Site 1 and Site 2 for individuals caught in the first twelve months of trapping (Wilcoxon signed rank test paired by number of months present $\left.\mathrm{Z}_{(\mathrm{n}=12)}=1.17, \mathrm{p}=0.24\right)$. Of the individuals caught during only one month, $65.4 \%$ and $63.5 \%$ were immature at Site 1 and 2 respectively. Individuals which were immature at first capture were never caught for more than six months with the majority only present for around four months. On average individuals caught in at least two months were present for four months (males; $\bar{X}=4.20$ months, $\mathrm{se}=0.31, \mathrm{n}=147$ : females; $\bar{X}=4.10$, se $=0.32, \mathrm{n}=124$ ). Five percent of individuals were present for more than 12 months.

\subsubsection{Rattus lutreolus}

The number of $R$. lutreolus caught each month at Site 1 (Fig. 2b) ranged from 15 to 37 individuals (3.5/ha to 8.5/ha). Prior to the fire at Site 2,20 to 28 individuals $(\sim 7.0 /$ ha) were present with around 5 individuals $(\sim 1.4 / \mathrm{ha})$ found each month after the November 1994 wildfire (Fig. 2b). No population trend was detected at Site 1 (runs test, $u_{0.05(1), 9,11}=6, u=9$ ) with changes in the population explained by random fluctuation around the median. Population sizes were too low after November 1994 at site two to confidently perform any analysis. The dramatic decline in numbers at Site 2 , from around 25 prior to the fire to less than five after, resulted in a difference between the capture densities at the two sites $\left(\mathrm{t}_{0.05,22}=5.90, \mathrm{p}<0.001\right)$.

The $R$. lutreolus populations were predominately mature individuals with more than $60 \%$ of the population mature in all months and greater than $80 \%$ mature in 15 of the 23 months. The occurrence of pregnant females suggested breeding occurred during spring and summer with breeding at Site 2 recorded from late winter to spring. Captures of pregnant females were recorded in 8 months at Site 1 with a maximum of three individuals in October 1995 and three individuals at Site 2.

Recently independent juveniles were found to enter the population from October to December and as late as February each year at Site 1 and from September until the fire at Site 2 . These individuals only accounted for $17 \%$ of captures at Site $1(n=161)$ with $64.6 \%$ being mature individuals with head-body lengths ranging from 110 to $190 \mathrm{~mm}(159.32 \pm 17.22, \mathrm{n}=103)$. Seventy-seven of the 94 individuals recruited into the population at Site 2 were mature with only 7.4\% (seven individuals) a direct result of breeding. Newly recruited individuals (from breeding and immigration) accounted for around $20 \%$ of the monthly population outside breeding periods and $50 \%-60 \%$ during breeding. Recruitment from breeding added 28 individuals to the population at Site 1 . Of these, 13 individuals (46.4\%) were not caught again and a further six individuals were only caught in one additional month. Of the remaining nine individuals, three were found to reach maturity $(140 \mathrm{~mm})$. This suggests that juvenile mortality was high or there was a degree of emigration soon after individuals became independent.

\subsection{Effects of fire}

\subsubsection{Melomys burtoni}

Of the 46 individuals present at Site 2 immediately before the fire, $25(54.3 \%)$ were found three weeks afterwards, with a further 11 individuals caught for the first time in December 1994. Thus, $M$. burtoni individuals were able to survive the passing of the fire and the population was able to persist at the burned site after the fire. The habitat type in which individuals were located influenced their ability to withstand wildfire. Twenty four out of the 25 individuals recaptured after the fire and nine of the 11 new captures were caught in the swamp based vegetation zones. Therefore $91.6 \%$ of individuals caught three weeks after the fire were in the moist vegetation zones which consisted 
of a spongy ground layer of root material unburned by the fire providing tunneling and food resources. Of the 21 individuals caught prior to the fire and never caught again, $16(76.2 \%)$ were from the drier vegetation zones with a sandy substrate. Further, six of the recaptures found in the moist habitats after the fire used the dry habitats prior to the fire. The fire had little influence on the distribution of surviving individuals with average capture locations before and after the fire separated by less than $50 \mathrm{~m}$ for all recaptured individuals and less than $30 \mathrm{~m}$ for 15 of the 25 individuals. While the M. burtoni population declined over the eight months preceding the fire, the trend and abundance was comparable with the unburned site. The population structure with respect to sex and reproductive condition was also similar to that of the unburned site after the fire. The fire appeared to have little overall effect on the $M$. burtoni population of Site 2 .

At the unburned site (Site 1), 30 individuals were caught for the first time immediately after the fire in December 1994, which was approximately three times the number of new captures than observed in any other month after the initial population was accounted for and twice the largest number found at Site 2 . While the fire coincided with increased breeding activity, only eight (27\%) of the individuals had head-body lengths less than $80 \mathrm{~mm}$ and were classified as a direct result of breeding. Twenty-two of the individuals caught for the first time were not caught again. This group of new capture individuals at the unburned site was also significantly smaller in head-body length $(\overline{\mathrm{X}}=$ 92.5 , se $=3.75)$ than the population present after the fire at Site $2(\bar{X}=$ 112.9 , se $=3.74, \mathrm{t}=3.63$, d.f. $=56, \mathrm{p}<0.001$ ) and the remainder of individuals at Site $1(\overline{\mathrm{X}}=115.6$, se $=3.10, \mathrm{t}=4.72$, d.f. $=54$, $\mathrm{p}<0.001$ ) suggesting a juvenile sub-set of the population immigrated with $70 \%$ of the new captures in December identified as immature.

Given that the influx of individuals was not explained by breeding, 22 of the new individuals likely immigrated into Site 1, most likely from the north in an attempt to escape the fire. Migration from other areas seemed unlikely, as areas south of Site 1 were unburned, the beach and dunes were to the east and a large area of open heathland and pine plantation where $M$. burtoni occur in low numbers (previous study, unpublished) lay to the west (Fig. 1). The number of individuals found to move between the two study sites both within and between trapping periods was low for both species. None of these movements occurred between November and December 1994 and no individuals caught at Site 1 were previously caught at Site 2 . Movement around Site 2 during the fire also suggested that there was limited emigration from the moist habitats of the burned site.

\subsubsection{Rattus lutreolus}

Prior to the fire at Site 2, the site had a stable population of approximately 20 individuals suggesting that the two study sites were capable of supporting similar populations due to similar areas of suitable intermittently inundated swamp habitat. The fire had an immediate influence with the population declining from 26 to 3 individuals. Although the population was reduced, individuals present three weeks after the fire remained at the burned site for the remaining 19 months. While 51 individuals were caught in the months after the fire at the burned site, only two to nine individuals (average 5.7) were caught in any month, well below the 20 to 30 individuals caught each month at Site 1 . The post-fire population exhibited a high degree of turnover and comprised almost entirely adult individuals, making monthly recruitment similar to death or emigration at the burned site. The low number of juveniles considered to be recently born $(110 \mathrm{~mm}$ or less) was most likely a result reduced breeding success or juvenile mortality. A disruption to breeding was expected given that the fire occurred during the breeding season. The population failed to increase as a result of immigration by September 1995 when breeding activity was again expected. Between August 1995 and February 1996, there were three or less mature females present each month limiting any breeding potential.

Twenty-four new individuals were caught at the unburned site three weeks after the fire of which 13 were mature and none resulted from breeding. Seven of these 24 individuals were never caught again. This was the largest number of new individuals caught at the site with less than eight new individuals recorded in 18 of the 23 months.

\section{Discussion}

The two study sites were separate and considered isolated with respect to individual movements. Nevertheless, they were subjected to the same environmental processes, and similarities between the populations at each site were found prior to the wildfire in the reproductive structure, breeding activity, abundances, and population trends of both species. Thus, the before-after, burned-unburned aspects of our study allowed valuable insight to be gained into movements, the effect of fire and population trends resulting from fire.

\subsection{Population dynamics}

Even without fire, population stability over time, as was witnessed in the R. lutreolus population at Site 1, does not necessarily occur. While the $M$. burtoni population fluctuated, there was limited immigration into the population with breeding all year round, but particularly in the spring and summer months, and the recruitment into the population was predominantly by immature individuals. The population trends were therefore associated with local site population changes rather than immigration. The majority of $R$. lutreolus recruitment was by mature individuals with either high juvenile mortality or the emigration of juveniles from the optimal habitats. Very few of these individuals were found in other areas of the study site so initial dispersal would be across significant distances. Given that recruitment from breeding by $R$. lutreolus was low and juveniles did not persist in place for more than five months, immigration as a result of a mobile portion of the population may be important for the maintenance of populations at each site. This was especially evident at Site 2 after the fire where there was a high turnover of a small population consisting almost entirely of adult individuals. Mature individuals of both species were found to persist in the study area for a number of months with some M. burtoni found for almost the duration of the study. Individual movements suggested that both species were reasonably sedentary based upon the length time individual $M$. burtoni were present, the proportion of individuals caught in more than one trapping session, and the limited movement between the two study sites only $228 \mathrm{~m}$ apart. Even though fire often results in individuals changing the area they use, our study only revealed a temporary movement of individuals into the unburned site immediately after the fire. This occurred with both $M$. burtoni and $R$. lutreolus, with the effect more pronounced for $M$. burtoni. These individual movements may have been small in actuality, as none of our marked individuals were found to move between the sites.

\subsection{Response to wildfire}

A species' ability to tolerate wildfire may be more related to its ability to use the modified habitat than simply survive fire. Thus, the fire at site 2 provided an opportunity to study the small mammals' response to a major habitat modification. $M$. burtoni appeared to survive the wildfire by burrowing into the damp, spongy layer present in the swamp zones, and were therefore present in the same locations before and after the fire. Whether $R$. lutreolus also used this structure to survive the passing of the fire is unknown as few individuals were found three weeks after the fire.

By removing the majority of vegetation, fire reduces food availability and can cause a collapse in herbivorous rodent numbers (Butcher and Dempster, 1970; Catling, 1986; Newsome et al., 1975). Clearly, M. burtoni were able to find sufficient food following the fire. Declines in $R$. lutreolus populations after fire have previously been reported (e.g., Catling, 1984; Monamy and Fox, 2000). Whether the 
decline in $R$. lutreolus abundance at our burned site was due to removal of a food source was not determinable. Given that the species is known to eat monocot leaves and stems, which survived the fire in the moist ground layer and quickly recovered following the fire, we believe loss of food was unlikely to have led to the low numbers after the fire.

Fire causes major structural changes to habitats, and population recovery after fire ultimately depends on the pattern of recovery of the vegetation (Karolak, 2005; Lindenmayer et al., 2005; Land for Wildlife Queensland, 2016b; Christensen et al., 1981). R. lutreolus have been reported to be absent from heathland areas after fire for around three years while the vegetation structure preferred by the species recovered (Catling, 1986; Monamy and Fox, 2000). The preference of this species for areas with high ground cover that permits a system of runways in the vegetation may account for the low numbers recorded after the fire (Braithwaite and Lee, 1979; Catling, 1986; Fox and Monamy, 2007; Monamy and Fox, 2010). In this study, R. lutreolus appeared immediately after the fire, but the population still had not recovered after considerable vegetation regrowth 18 months after the fire. The rapid appearance of the species (in low numbers) was probably due to the close proximity of unburned habitat $50 \mathrm{~m}$ south. However, Fox (1982) found little colonisation even when individuals were present $50 \mathrm{~m}$ away. We found no period when individuals were absent, as reported in other studies (Fox, 1982; Catling, 1984). Fox (1982) reported that successful breeding in $R$. lutreolus did not occur for five years post-fire. As already indicted, we found recruitment from breeding to be low with juveniles not persisting at the site for more than five months, and dispersal appeared to be the primary source of recruitment after the fire. Nonetheless, the number of individuals entering the population from outside the burned site was low. Fox and Monamy (2007) and Monamy and Fox $(2000,2010)$ found $R$. lutreolus to be a late serial stage specialist dependent on recovery of vegetative and cover for recolonization, rather than time since a burn or other disturbance. Monamy and Fox (2000) found the species recolonized 3.6 years after one fire, but only 4 months after another, with the latter example considered an anomaly based on rapidity of vegetative recovery. Despite vegetative regrowth during the 18 months we studied the populations after the wildfire, our results showing slow $R$. lutreolus population recovery concur with the above studies and also suggest late vegetative stages are required for full population recovery.

On a local scale, $M$. burtoni, which were located in the moist, swamp habitats, were able to escape the fire. Limited movements around the time of the fire allowed these individuals to remain in the same areas after the fire. On a broad scale, this habitat is only available in a band of approximately $80 \mathrm{~m}$ west of the dunes. While small areas such as drainage channels offer similar protection, the vast majority of habitats in the area surrounding the study sites could not sustain individuals during and after a fire. The habitats that did not support individuals after the fire were the dry open heathlands and woodlands. Large areas of these habitats occur around the study sites and support at least $M$. burtoni in low densities. Increased activity in response to the fire is the most likely reason for the influx of individuals into the unburned site immediately after the fire, as individuals of both species had to escape the fire or perish.

Also of consequence environmentally, the coastal heathland region in which our study took place is exposed to pressures from regional development, human population increases, and climate change, all of which can impact and modify habitats. Our results might also provide insight on population responses to other such potential forms of habitat modification in this region, as well as providing baseline information from which to continue monitoring these small mammal populations (e.g., Fox and Monamy, 2007).

\subsection{Population monitoring considerations}

This research centered on monitoring populations of two species of rodents. Besides the general ecological information obtained and the information obtained on wildfire responses, we also gained insights about the population monitoring process itself. When conducting a study involving the trapping and marking of wildlife, the complexity and variability involved in sampling mobile populations require appropriate effort to be made to ensure trapping techniques lead to accurate population estimates, and not artifacts of methodology. Possible errors and inefficiencies of the estimation techniques associated with mark-recapture methods are well-known (e.g., Otis et al., 1978; Hammond and Anthony, 2006; White et al., 1982). Investigators should be particularly mindful of CAPTURE's small sample limitations (e.g., Hammond and Anthony, 2006). In fact, and related to this, McKelvey and Pearson (2001) reported that $67 \%$ of the small mammal studies in their thorough five-year literature review used population indices rather than estimators of population size, but that $98 \%$ of small mammal studies produced insufficient data for valid mark-recapture population estimates (thereby implying a high proportion of published mark-recapture results were not valid).

The availability of previous data and conducting a pilot study highlighted the value of prior trapping data. This allowed us to optimize the number of traps and trapping nights to minimize the variability in capture probabilities that could be controlled through study design, with this optimization a trade-off between maximizing captures and recaptures, while not allowing immigration and emigration to violate closure assumptions and also avoiding temporal variation in capture probabilities. The prior trapping experience also helped determine a sufficient number of traps to avert influencing an individual's access to traps through trap saturation. The trapping grid layout was designed to avoid excluding individuals or biasing probabilities of capture. Nevertheless, our study provided a field-based demonstration of inherent problems. Even with previous trapping information, we were unable to prevent localized trap saturation and the presence of heterogeneous capture probabilities. The population sizes and numbers of animals we captured each month were not sufficient for CAPTURE to produce reliable results, especially when considering that, as already mentioned, CAPTURE often does not select the correct model for data sets with $<50$ individuals, thereby resulting in biased estimates (Hammond and Anthony, 2006; Menkens and Anderson, 1988; White et al., 1982). Thus, we turned to an alternative, well-recognized means to track relative abundance of our study populations.

The capture frequency and relative density calculated from the cumulative catch provided a suitable index of population size for our data, as sophisticated estimations could not be made due to populations being too small to calculate population estimates with the given (heterogeneous) capture probabilities. The number of unique individuals captured each month most likely underestimated the true population, but allowed examination of population changes. That such methods well-track population abundance and population estimates has been well-documented by others. For example, Hopkins and Kennedy (2005) found the number of unique individuals captured to "provide patterns of population trends proportional to those observed from estimates of absolute abundance," and Caughley and Sinclair (1994) stated that frequency of capture as a relative density index is a valid initial approach for estimating populations. Madsen and Shine (1999) used the number of unique individuals caught as the population estimate, because population estimation models were not suitable even though monthly populations often exceeded 100 individuals and the population was trapped with confidence. Similarly, McKelvey and Pearson (2001) also found that "the number of unique individuals captured" as an index frequently outperformed the mark-recapture estimators they tested, was correlated with the other estimators, has a known negative bias, is bounded between zero and the true population, and appears robust to changes in sources of variation. These results support the use of number of unique individuals captured as a suitable index of population size when it is not possible to use other estimators.

If population demographics are necessary to meet monitoring objectives, then identification of individual animals is likely necessary. 
However, when population demographics are not necessary other indexing methods besides the number of unique individuals might also be available for population monitoring with statistical properties and methodologies developed for some (e.g., Engeman, 2005), and methods have been described for validating the procedures in the absence of known populations (Allen and Engeman, 2015). In particular, a variety of approaches have been developed for monitoring many rodent species (e.g., Engeman and Whisson, 2006; Whisson et al., 2005), with an index based on camera trap data most likely to provide the ability to simultaneously monitor multiple species of rodents (e.g., Baldwin et al., 2014). In any case, a new approach would require testing and validation (Allen and Engeman, 2015). Yet, the mark-recapture approach provides a range of information pertaining to a population, and can be used in conjunction with simple estimates to gain a better understanding of population size and processes, even with difficulties like those we encountered for avoiding violation of assumptions (which were apparent even for Melomys, one of the best candidates for markrecapture estimation amongst Australian small mammals).

\section{Author contributions}

$\mathrm{AL}$ and JW contributed to the conceptual design of the study. AL designed and carried out the field methods, and analysed the data. AL, JW, RE contributed to conceptualization of the paper. AL and RE wrote the paper.

\section{Acknowledgements}

We thank the numerous people involved in undertaking this field study, particularly John White. We are grateful for the comments and suggestions of Beth Crase, Kerrilee Pywell, Alan Andersen and three anonymous reviewers. This study was conducted under Queensland Department of Environment and Heritage permits T00988, T01202, T01204 and E1/000599/95/SAA and with the approval of the Queensland University of Technology Biomedical Ethics Committee (Ref No QUT 621/1A).

\section{Appendix A. Supplementary data}

Supplementary data related to this article can be found at http://dx. doi.org/10.1016/j.actao.2018.03.006.

\section{References}

Allen, L.R., Engeman, R.M., 2015. Evaluating and validating abundance monitoring methods in absence of populations of known size. Environ. Sci. Pollut Control Ser. 22, 2907-2915.

Baldwin, R.A., Quinn, N., Davis, D.H., Engeman, R.M., 2014. Effectiveness of rodenticides for managing invasive roof rats and native deer mice control in orchards. Environ. Sci. Pollut. Control Ser. 21, 5795-5802.

Baverstock, P.R., Watts, C.H.S., Adams, M., Cole, S.R., 1981. Genetical relationships among Australian rodents (Muridae). Aust. J. Zool. 29, 289-303.

Braithwaite, R.W., Lee, A.K., 1979. The ecology of Rattus lutreolus I. A Victorian heathland population. Aust. Wildl. Res. 6, 173-189.

Butcher, A.D., Dempster, J.K., 1970. Fire and Management of Wildlife in 2nd Fire Ecology Symposium: Forst Commission Victoria. Monash University Melbourne.

Catling, P.C., 1984. Extinction and recolonization of heathland by small mammals after fire - a strategy of resilience. In: Proceedings of the 4th International Conference on Mediterranean Ecosystems, pp. 27-28.

Catling, P.C., 1986. Rattus lutreolus, colonizer of heathlands after fire in the absence of Pseudomys species? Aust. Wildl. Res. 13, 127-139.

Caughley, G., Sinclair, A.R.E., 1994. Wildlife Ecology and Management. Blackwell Science, Cambridge.

Christensen, P., Recher, H., Hoare, J., 1981. Responses of open forests (dry sclerophyll forests) to fire regimes. In: Gill, A.M., Groves, R.H., Noble, I.R. (Eds.), Fire and the Australian Biota. Australian Academy of Science, Canberra, pp. 367-393.

Cowley, R.D., Heislers, A., Ealey, E.H.M., 1969. Effects of fire on wildlife. Vic. Resour. 11, $18-22$.

Dyer, B.C., Clarke, A.R., Fuller, S.J., 2011. Population Dynamics, Diet and Pest Status of the Grassland Melomys (Melomys Burtoni) in Northern Queensland Sugarcane Crops Wildlife Research, vol. 38. pp. 330-337.

Elsol, J.A., Sattler, P.S., 1979. Moreton region vegetation map series. Explanatory booklet for
Caloundra. Botany Branch. Queensland Department of Primary Industries, Brisbane.

Engeman, R.M., 2005. Indexing principles and a widely applicable paradigm for indexing animal populations. Wildl. Res. 32, 203-210.

Engeman, R.M., Whisson, D.A., 2006. Using a general indexing paradigm to monitor rodent populations. Int. Biodeterior. Biodegrad. 58, 2-8.

Fox, B.J., 1979. Growth and development of Rattus lutreolus (Rodentia: Muridae) in the laboratory. Aust. J. Zool. 27, 945-957.

Fox, B.J., 1982. Fire and mammalian secondary succession in an Australian coastal heath. Ecology 63, 1332-1341.

Fox, B.J., Monamy, V., 2007. A review of habitat selection by the swamp rat, Rattus lutreolus (Rodentia: Muridae). Austral Ecol. 32, 837-849.

Geffen, E., Rowe, K.C., Yom-Tov, Y., 2011. Reproductive rates in australian rodents are related to phylogeny. Supporting information table S1. PLoS One 6 (4) e19199.

Gill, A.M., 1975. Fire and the australian flora: a review. Aust. For. 38 (1), 4-25.

Hammond, E.L., Anthony, R.G., 2006. Mark-recapture estimates of population parameters for selected species of small mammals. J. Mammal. 87 (3), 618-627.

Hopkins, H.L., Kennedy, M.L., 2005. An assessment of indices of relative and absolute abundance for monitoring populations of small mammals. Wildl. Soc. Bull. 32, 1289-1296.

Jolly, G.M., 1965. Explicit estimates from capture-recapture data with both death and immigration - stochastic model. Biometrika 52, 225-247.

Karolak, S., 2005. Flame grilled specials: how Australian animals find food after bushfires. Wildlife Australia Magazine 42, 30-34.

Knox, E.J., 1978. A note on the identification of Melomys species (Rodentia:Muridae) in Australia. J. Zool. 185, 276-277 London.

Land for Wildlife Queensland, 2016a. Note F2: Fire, Flora and Fungi. SEQ Catchments, Brisbane.

Land for Wildlife Queensland, 2016b. Note F3: Fire and Fauna. SEQ Catchments, Brisbane.

Lindenmayer, D.B., Cunningham, R.B., Peakall, R., 2005. The recovery of populations of bush rat Rattus fuscipes in forest fragments following major population reduction. J. Appl. Ecol. 42, 649-658.

Lunney, 1978. Ecology of Rattus Lutreolus. Unpubl. M.S. thesis. Univ. Sydney, Sydney.

Madsen, T., Shine, R., 1999. Rainfall and rats: climatically driven dynamics of a tropical roden population. Aust. J. Ecol. 24, 80-89.

McDougall, W.A., 1946. An investigation of the rat pest problem in Queensland canefields: 4. Breeding and life histories. Qld. J. Agric. Sci. 3, 1-43.

McKelvey, K.S., Pearson, D.E., 2001. Population estimation with sparse data: the role of estimators versus indices revisited. Can. J. Zool. 79, 1754-1765.

Menkens Jr., G.E., Anderson, S.H., 1988. Estimation of small mammal population size. Ecology 69, 1252-1259.

Monamy, V., 1995. Population dynamics of, and habitat use by, Australian native rodents in wet sclerophyll forest, Tasmania. Wildl. Res. 22, 647-660.

Monamy, V., Fox, B.J., 2000. Small mammal succession is determined by vegetation density rather than time elapsed since disturbance. Austral Ecol. 25, 580-587.

Monamy, V., Fox, B.J., 2010. Responses of two species of heathland rodent to habitat manipulation: vegetation density thresholds and the habitat accommodation model. Austral Ecol. 35, 334-347.

Newsome, A.E., Mcilroy, J., Catling, P., 1975. The effects of an extensive wildfire on populations of 20 ground vertebrates in south-east Australia. Proc. Ecol. Soc. Aust. 9, 107-123.

Otis, D.L., Burnham, K.P., White, G.C., Anderson, D.R., 1978. Statistical inference from capture data on closed animal populations. Wildl. Monogr. 62, 1-135.

Redhead, T.D., 1973. A re-assessment of the rat problem in north Queensland cane fields with emphasis on the ecology and reproduction of Melomys littoralis (Lommberg). MSc Thesis. James Cook University, Queensland.

Seber, G.A.F., 1965. A note on the multiple-recapture census. Biometrika 52, 249-259.

Sokal, R.R., Rohlf, F.J., 1995. Biometry, third ed. WH Freeman and Co, New York.

South East Queensland Fire and Biodiversity Consortium, 2006. Living with Fire Native Wildlife. South East Queensland Fire and Biodiversity Consortium.

South East Queensland Fire and Biodiversity Consortium, 2014. Living with Fire Recommended Fire Regimes (Fact Sheet 3). South East Queensland Fire and Biodiversity Consortium.

Strahan, R., 1995. Swamp Rat. Mammals of Australia. Smithsonian Institution Press, Washington D.C.

Taylor, J.M., Horner, B.E, 1973. Reproductive characteris-tics of wild of native australian Rattus (rodentia, Muridae). Aust. J. Zool. 21, 437-475.

Watson, P., 2001. The Role and Use of Fire for Biodiversity Conservation in Southeast Queensland: Fire Management Guidelines Derived from Ecological Research. SEQ Fire \& Biodiversity Consortium, Brisbane.

Watson, P., 2002. Fire in Bushland Conservation: the Role of Fire in the Landscape and How We Can Manage it for Biodiversity Conservation. SEQ Fire \& Biodiversity Consortium, Brisbane.

Watts, C.H.S., 1982. The husbandry of Australian Rattus. In: Evans, D.D. (Ed.), The Management of Australian Mammals in Captivity. Zoo1. Board Victoria, pp. 177-179 Melbourne.

Watts, C.H.S., Aslin, H.J., 1981. The Rodents of Australia. Angus and Robertson Publishers, London.

Watts, C.H.S., Kemper, C.M., 1989, The Muridae. In: Walton, D.W. Richardson, B.J. (Eds.), Fauna of Australia. Australian Government Publishing Service, Canberra, pp. 939-956.

Whisson, D.A., Engeman, R.M., Collins, K., 2005. Developing relative abundance techniques (RATs) for monitoring rodent populations. Wildl. Res. 32 (Special issue: use of indices to monitor wildlife populations), 239-244.

White, G.C., Anderson, D.R., Burnham, K.P., Otis, D.L., 1982. Capture-recapture and Removal Methods for Sampling Closed Populations. Los Alamos National Laboratory, Los Alamos, NM.

White, G.C., Burnham, K.P., 1999. Program MARK: survival estimation from populations of marked animals. Hous. Theor. Soc. 46, 120-139.

Woinarski, J.C.Z., Palmer, C., Fisher, A., Southgate, R., Masters, P., Brennan, K., 1999. Distribution patterning of mammals on the wessel and English company islands, arnhem Land, northern territory, Australia. Aust. J. Zool. 47, 87-111. 